\title{
EDITORIAL
}

\section{REVIEW OF THE INTERNATIONAL DEFINITION OF SOCIAL WORK}

Since the adoption of the international definition by the International Association of Schools of Social Work (IASSW) and the International Federation of Social Workers (IFSW) in 2001 there have been criticisms. The main criticisms centered on the definition representing a Western bias with its emphasis on individual rights and social change, to the exclusion of collective rights and the societal imperatives for continuity, stability and social cohesion. The current definition reads as:

The SW profession promotes social change, problem-solving in human relationships and the empowerment and liberation of people to enhance wellbeing. Utilising theories of human behaviour and social systems, social work intervenes at the points where people interact with their environments. Principles of human rights and social justice are fundamental to social work.

For the past few years the IFSW and the IASSW have jointly engaged in processes of consultation to review the above definition. Given the contextual realities of social work, and the fact that understanding and responding to socio-economic, political and cultural diversities are the hallmarks of the social work profession, questions have been raised about the wisdom of having a single definition on a global level. Yet, there is a sense that there must be some unifying characteristics of the profession that grant legitimacy to the existence of international bodies such as the IASSW and the IFSW. There is also a sense that we have some shared visions on a global level when we speak of the social work profession; that there is a common language that unites us a profession on a global level. Even with acceptance, in principle, of the need for a global definition, the consultation processes have generated huge debates about what we include or exclude in a global definition, with every word in the definition being scrutinized, and its relevance for all contexts critiqued. Recognising the diversities of contexts the Joint Definition Committee of the IASSW and the ISFW have taken a principled decision to create space for layered definitions at the global, regional and national levels. As it is not possible to have a single definition to accommodate the particularities of every region and/or nation state, the Committee decided to have a brief, concise and aesthetically appealing definition that will be easily translatable into different languages while encouraging the amplification of the definition at regional and/or national levels. Having spent several years on reviewing the current definition, the IASSW and IFSW have agreed on the following international definition of the social work profession, that reflect both subtle and substantive changes from the current definition, with the accompanying detailed commentary to go out for a last round of broad consultation.

\section{Proposed new international definition of the social work profession}

The social work profession facilitates social change and development, social cohesion, and the empowerment and liberation of people. Principles of social justice, human rights, collective responsibility and respect for diversities are central to social work. Underpinned by theories of social work, social sciences, 
humanities and indigenous knowledges, social work engages people and structures to address life challenges and enhance wellbeing.

The above definition may be amplified at national and/or regional levels.

\section{COMMENTARY}

The commentary serves to unpack the core concepts used in the definition and is detailed in relation to the social work profession's core mandates, principles, knowledge and practice.

\section{CORE MANDATES}

The social work profession's core mandates include facilitating social change, social development, social cohesion, and the empowerment and liberation of people.

The social work profession recognizes that interconnected historical, socio-economic, cultural, spatial, political and personal factors serve as opportunities and/or barriers to human wellbeing and development. Structural barriers contribute to the perpetuation of inequalities, discrimination, exploitation and oppression. The development of critical consciousness through reflecting on structural sources of oppression and/or privilege and developing action strategies towards addressing structural and personal barriers are central to emancipatory practice where the goals are the empowerment and liberation of people. In solidarity with those who are disadvantaged, the profession strives to alleviate poverty, liberate the vulnerable and oppressed, and promote social inclusion and social cohesion.

The social change mandate is based on the premise that social work intervention takes place when the current situation, be this at the level of the person, family, small group, community or society, is deemed to be in need of change and development. It is driven by the need to challenge and change those structural conditions that contribute to marginalization, social exclusion and oppression. Social change initiatives recognize the place of human agency in advancing human rights and economic, environmental, and social justice. The profession is equally committed to the maintenance of social stability, insofar as such stability is not used to marginalize, exclude or oppress any particular group of persons.

Social development is conceptualized to mean strategies for intervention, desired end states and a policy framework, the latter in addition to the more popular residual and the institutional frameworks. It is based on holistic biopsychosocial, spiritual assessments and interventions that transcend the micro-macro divide, incorporating multiple system levels and inter-sectorial and inter-professional collaboration. It prioritizes sociostructural and economic development, and does not subscribe to conventional wisdom that economic growth is a prerequisite for social development.

\section{PRINCIPLES}

The overarching principles of social work are respect for the inherent worth and dignity of human beings, doing no harm, respect for diversity and upholding human rights and social justice. 
Advocating and upholding human rights and social justice is the motivation and justification for social work. The social work profession recognizes that human rights need to coexist alongside collective responsibility. The idea of collective responsibility highlights the reality that individual human rights can only be realized on a day-to-day basis if people take responsibility for each other and the importance of creating reciprocal relationships within communities. Therefore a major focus of social work is to advocate for the rights of people at all levels, and to facilitate outcomes where people take responsibility for each other's wellbeing, realize and respect the inter-dependence among people and between people and the environment.

Social work embraces first, second and third generation rights. First generation rights refer to civil and political rights such as free speech and conscience and freedom from torture and arbitrary detention; second generation to socio-economic and cultural rights that include the rights to reasonable levels of education, healthcare, and housing and minority language rights; and third generation rights focus on the natural world and the right to species biodiversity and inter-generational equity. These rights are mutually reinforcing and interdependent, and accommodate both individual and collective rights.

In some instances "doing no harm" and "respect for diversity" may represent conflicting and competing values, for example where in the name of culture the rights, including the right to life, of minority groups such as women and homosexuals, are violated. The Global Standards for Social Work Education and Training deals with this complex issue by advocating that social workers are schooled in a basic human rights approach, with an explanatory note that reads as:

Such an approach might facilitate constructive confrontation and change where certain cultural beliefs, values and traditions violate peoples' basic human rights. As culture is socially constructed and dynamic, it is subject to deconstruction and change. Such constructive confrontation, deconstruction and change may be facilitated through a tuning into, and an understanding of particular cultural values, beliefs and traditions and via critical and reflective dialogue with members of the cultural group vis-à-vis broader human rights issues.

\section{KNOWLEDGE}

Social work is both interdisciplinary and transdisciplinary, and draws on a wide array of scientific theories. "Science" is understood in this context in its most basic meaning as "knowledge". Social work draws on its own constantly developing theoretical foundation, as well as theories from other human sciences, including but not limited to community development, social pedagogy, administration, anthropology, ecology, economics, education, management, nursing, psychiatry, psychology, public health, and sociology. The uniqueness of theories in social work is that they are applied and emancipatory. Much of social work theory is co-constructed with service users in an interactive, dialogic process and therefore informed by specific practice environments.

This proposed definition acknowledges that social work is informed not only by specific practice environments and Western theories, but also by indigenous knowledges. Part of 
the legacy of colonialism is that Western theories and knowledges have been exclusively valorised, and indigenous knowledges have been devalued, discounted, and hegemonised by Western theories and knowledge. The proposed definition attempts to halt and reverse that process by acknowledging that indigenous peoples in each region, country or area carry their own values, ways of knowing, ways of transmitting their knowledges, and have made invaluable contributions to science. Social work seeks to redress historic Western scientific colonialism and hegemony by listening to and learning from indigenous peoples around the world. In this way social work knowledges will be co-created and informed by indigenous peoples, and more appropriately practiced not only in local environments but also internationally. Drawing on the work of the United Nations, the IFSW defines indigenous peoples as follows:

- They live within (or maintain attachments to) geographically distinct ancestral territories.

- They tend to maintain distinct social, economic and political institutions within their territories.

- They typically aspire to remain distinct culturally, geographically and institutionally, rather than assimilate fully into national society.

- They self-identify as indigenous or tribal. (http://ifsw.org/policies/indigenous-peoples)

\section{PRACTICE}

The participatory methodology advocated in social work is reflected in "Engages people and structures to address life challenges and enhance wellbeing." As far as possible social work supports working with rather than for people. Consistent with the social development paradigm, social workers utilize a range of skills, techniques, strategies, principles and activities at various system levels, directed at system maintenance and/or system change efforts. Social work practice spans a range of activities including various forms of therapy and counseling, group work, and community work; policy formulation and analysis; and advocacy and political interventions. From an emancipatory perspective, that this definition supports social work strategies are aimed at increasing people's hope, self-esteem and creative potential to confront and challenge oppressive power dynamics and structural sources of injustices, thus incorporating into a coherent whole the micro-macro, personal-political dimension of intervention. The holistic focus of social work is universal, but the priorities of social work practice will vary from one country to the next, and from time to time depending on historical, cultural, political and socio-economic conditions.

It is the responsibility of social workers across the world to defend, enrich and realize the values and principles reflected in this definition. A social work definition can only be meaningful when social workers actively commit to its values and vision.

Please send your responses to Professor Vishanthie Sewpaul (Chair of the International Definition Committee on behalf of IASSW) by 30 July 2013. 
xiv

E-mail: Sewpaul@ukzn.ac.za

Vishanthie Sewpaul (PhD) (Senior Professor)

University of KwaZulu-Natal

School of Applied Human Sciences

Howard College Campus

Durban, 4041

South Africa 